Revista Universo Contábil, ISSN 1809-3337

FURB, v. 6, n.2, p. 06-26, abr./jun., 2010

doi:10.4270/ruc. 2010210

Disponível em www.furb.br/universocontabil

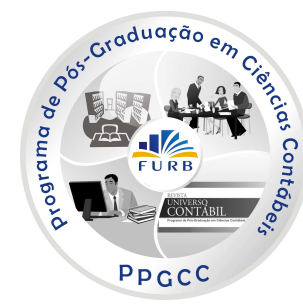

\title{
SISTEMAS DE CONTROLE GERENCIAL EM EMPRESAS BRASILEIRAS INTERNACIONALIZADAS: O CASO DE UMA EMPRESA DE MATERIAL ELÉTRICO*
}

\section{MANAGEMENT CONTROL SYSTEMS IN INTERNATIONALIZED BRAZILIAN COMPANIES: THE CASE OF A ELECTRICAL SUPPLY COMPANY}

\author{
Angela Siebra Bouças \\ Mestranda em Ciências Contábeis da UERJ \\ Endereço: Rua Pedra Branca, 505 - Taquara \\ CEP: 22715-330 - Rio de Janeiro/RJ - Brasil \\ E-mail: ansiebra@hotmail.com \\ Telefone: (21) 8750-3700
}

Josir Simeone Gomes

Doutor em Administração pela Universidade Federal do Rio de Janeiro Professor do Mestrado em Ciências Contábeis da UERJ Endereço: Travessa Visconde de Moraes, 199 - Botafogo CEP: 22260-080 - Rio de Janeiro/RJ - Brasil

E-mail: josirgomes@ superig.com.br Telefone: (21) 9871-7850

\section{RESUMO}

A internacionalização é um fenômeno mundial que está mudando a forma como os sistemas de controle gerencial devem ser conduzidos, a fim de que as empresas possam ser competitivas e atendam às necessidades da economia global. A intenção deste estudo é abordar as seguintes questões: Quais as características do sistema de controle gerencial em empresas brasileiras internacionalizadas? Que tipo de controle gerencial as empresas internacionalizadas adotam face à nova realidade de um ambiente internacional competitivo? Para responder a estas perguntas foi realizado um estudo de caso em que a abordagem foi feita com o intuito de captar a essência das características da internacionalização na empresa estudada. O estudo de caso escolhido é de uma empresa do setor elétrico. Foram coletados dados primários e secundários. Dados primários foram retirados de um questionário direcionado às pessoas envolvidas no processo de tomada de decisão da empresa. Posteriormente estes dados foram analisados para investigar o grau de afastamento ou proximidade que o controle gerencial da empresa estudada tem em relação à literatura

\footnotetext{
Artigo recebido em 16.02.2009. Revisado por pares em 20.03.2009. Reformulado em 22.07.2009. Recomendado para publicação em 29.07.2009 por Ilse Maria Beuren (Editora). Publicado em 30.06.2010. Organização responsável pelo periódico: FURB.
} 
trabalhada acerca das características dos sistemas de controle gerencial em empresas internacionalizadas. Há poucos pontos coincidentes entre aquilo que é apresentado na literatura e o que foi identificado na empresa estudada. Provavelmente pela falta de um sistema de controle gerencial adequado na empresa durante o processo de internacionalização e também fora dele, é que, mesmo tendo conquistado o mercado internacional da América Latina, a empresa não conseguiu manter a sua posição após a perda do contrato de parceria.

Palavras-chave: Controle gerencial. Internacionalização. Estudo de caso.

\section{ABSTRACT}

Internationalization is a worldwide phenomenon that is changing the way of management control systems should be conducted so that businesses can be competitive and meet the needs of the global economy. The intention of this work is to address the following questions: What are the characteristics of the management control systems in internationalized Brazilian companies? What kind of management control systems internationalized companies adopt in order to face the new reality of a competitive international environment? To answer these questions, a case study was done whose approach meant to capture the true essence of the internationalization characteristics in the company studied. The case study chosen is of a company in the energy sector. Primary and secondary data were collected. The Primary data were collected from a questionnaire directed to people who are involved in the decisionmaking process of the company. Subsequently, these data were analyzed to investigate the degree of proximity or remoteness that the managerial control of the company studied has in relation to the literature considered on the characteristics of managerial control systems in internationalized companies. There are few matching points between what is presented in the literature and what was identified in the company studied. Probably due to the lack of an adequate system of management control in the company during the process of internationalization and also out of it, even winning the of Latin American international market, the company failed to maintain its position after the loss of the partnership contract.

Keywords: Management control systems. Internationalization. Case study.

\section{INTRODUÇÃO}

As organizações multinacionais podem apresentar uma analogia entre as práticas de controle adotadas tanto em seu país de origem como nas operações existentes no exterior. Entretanto, existem diferenças culturais que podem influenciar a utilização dos sistemas e a forma como eles são projetados. Existe uma necessidade de adaptação no planejamento estratégico, na avaliação de desempenho, remuneração dos executivos, etc. (ANTHONY; GOVINDARAJAN, 2006, p. 906-907).

Além das diferenças culturais, cada seguimento empresarial tem suas características peculiares. Dessa forma, este estudo busca verificar a influência sofrida no sistema de controle gerencial de empresas brasileiras, em um caso específico, o caso da empresa do ramo de material elétrico, perante o processo de internacionalização.

Buscou-se explorar o grau de afastamento ou proximidade existente entre o controle gerencial da empresa estudada e aquilo que é apresentado na literatura sobre controle gerencial, além das alterações sofridas face à internacionalização.

Supõe-se que as empresas brasileiras atuando no mercado doméstico e que já operam em outros mercados fora do Brasil têm características desenvolvidas diferenciadas em seu projeto de sistema de controle gerencial. Assim, foi levantado o seguinte questionamento: 
qual a característica dos sistemas de controle gerencial existentes em uma empresa brasileira internacionalizada?

Através dos resultados apresentados nesse estudo pretende-se despertar o interesse dos estudiosos sobre a importância do sistema de controle gerencial no processo de tomada de decisão e nas atividades das empresas internacionalizadas.

\section{REVISÃO DA LITERATURA}

\subsection{Controle gerencial}

"A essência da organização é suas funções e seus relacionamentos. Isto é, o gerenciamento identifica o que deve ser feito para que a empresa possa alcançar seus objetivos, e então estabelece o relacionamento desejado entre as funções" (KEITH; KEITH, 1985 , p. 8). A organização é o instrumento que serve para que as pessoas possam ser produtivas. A organização deve ser homogênea e a empresa toda deve ser organizada da mesma forma, (DRUCKER, 1999, p. 19-20).

Para que as organizações funcionem de maneira que possam atingir os seus objetivos, é necessário que haja um controle de gestão. Esse controle serve para que os gerentes consigam garantir que a estratégia da empresa seja respeitada. $\mathrm{O}$ controle gerencial nada mais é do que um dos vários tipos de planejamento e controle de uma empresa, através da formulação de estratégias e controle das tarefas. É no controle gerencial que as estratégias adotadas serão obedecidas (ANTHONY; GOVINDARAJAN, 2006, p. 30 e 33-34; ).

O controle de gestão refere-se ao processo que resulta da inter-relação de um conjunto de elementos internos (formais e informais) e externos à organização que influem no comportamento dos indivíduos que formam parte da mesma. A atuação da administração pode ser muito importante no desenho de um sistema e na realização de um processo que permita influir decisivamente no comportamento das pessoas para que atuem de acordo com os objetivos negociados pela administração (GOMES, 1997, p. 23).

Esse controle permite que as atividades empresariais sejam realizadas em conformidade com as expectativas dos stakeholders, melhorando a competitividade da empresa. Ele pode ser muito ou pouco formalizado, espontâneo ou não, e com menor ou maior ênfase nos instrumentos de caráter financeiro, enquanto mecanismo de reforço de comportamento positivo e correção de rumo de resultados não desejados (GOMES; SALAS, 2001, p. 22).

\footnotetext{
O controle gerencial inclui várias atividades, como: (1) planejar o que a organização deve fazer; (2) coordenar as atividades de várias partes da organização; (3) comunicara informação; (4) avaliar a informação; (5) decidir se deve ser tomada a decisão, ou que decisão tomar; e (6) influenciar as pessoas para que alterem seu comportamento (ANTHONY; GOVINDARAJAN, 2006, p. 34).
}

O controle deve ser permanente, realizado pela gerência e por todos que fazem parte dela, não deve se limitar aos aspectos técnicos apenas, mas também, adequar-se à cultura organizacional e também deve ser utilizado de forma flexível (GOMES; SALAS, 2001, p. 24). A finalidade do controle gerencial é: 
necessário que o executivo obtenha a aprovação para isso. A estrita obediência ao orçamento não é necessariamente boa, e o desvio do orçamento não é necessariamente mau (ANTHONY; GOVINDARAJAN, 2006, p. 34).

No Quadro 1 apresentam-se as correntes teóricas sobre o controle organizacional conforme Gomes e Salas (2001).

\begin{tabular}{|c|c|c|}
\hline $\mathbf{N}^{\circ}$ & Ênfase & Características \\
\hline $\begin{array}{l}\text { Primeira } \\
\text { corrente }\end{array}$ & $\begin{array}{l}\text { Aspectos mais } \\
\text { formais do controle }\end{array}$ & $\begin{array}{l}\text { Origem na escola clássica de Taylor e Fayol } \\
\text { Entende que a implantação do controle permite o alcance da eficiência e } \\
\text { eficácia da organização }\end{array}$ \\
\hline $\begin{array}{l}\text { Segunda } \\
\text { corrente }\end{array}$ & $\begin{array}{l}\text { Aspectos } \\
\text { psicossociais } \\
\text { (motivacionais, } \\
\text { cognitivos) }\end{array}$ & $\begin{array}{l}\text { Controle associado à influência das teorias das relações humanas, } \\
\text { processamento humano da informação e teoria de sistemas abertos. } \\
\text { Destaque para a influência da contabilidade de gestão nas pessoas e } \\
\text { influência dos diferentes estilos de liderança no desenho e uso dos sistemas } \\
\text { de controle } \\
\text { Entende que os objetivos podem ser alinhados: objetivos individuais } \\
\text { congruentes com os objetivos da organização. Assim, melhora a motivação } \\
\text { e a capacidade de autocontrole das pessoas. }\end{array}$ \\
\hline $\begin{array}{l}\text { Terceira } \\
\text { corrente }\end{array}$ & $\begin{array}{l}\text { Aspectos culturais } \\
\text { presentes no } \\
\text { controle }\end{array}$ & $\begin{array}{l}\text { É vista como uma das forças guiando a tomada de decisão. } \\
\text { Alguns a consideram como uma variável interna (incorporada ao próprio } \\
\text { conceito de controle, permite a integração da organização e aumenta a } \\
\text { probabilidade dos comportamentos individual e organizacional se dirigirem } \\
\text { para o mesmo objetivo) e outros como uma metáfora que emerge da } \\
\text { própria organização (a contabilidade de gestão cria determinados } \\
\text { significados subjetivos e percepções que surgem da contínua interação } \\
\text { social entre os indivíduos, o sistema de controle é simbólico e pode } \\
\text { desempenhar um papel importante na criação de valores de caráter } \\
\text { nacional, importância aos processos de controle dos quais são descobertos, } \\
\text { valorizados e compartidos os diferentes objetivos e preferências pelos } \\
\text { indivíduos da organização). } \\
\text { A dinâmica organizacional é resultado da combinação de fatores formais e } \\
\text { não formais tantos internos como externos à própria organização. }\end{array}$ \\
\hline
\end{tabular}

Quadro 1 - Correntes teóricas sobre o controle organizacional

Fonte: adaptado de Gomes e Salas (2001, p. 28; 32-37).

As perspectivas de controle de gestão, apresentadas no Quadro 1, são classificadas da seguinte forma: a perspectiva racional está relacionada à primeira corrente, ela centra-se no estudo dos sistemas de controle, onde os paradigmas (maximização de lucros, ênfase nos aspectos formais da estrutura) e técnicas administrativas (orçamento, custos) são baseados nessa primeira abordagem; a segunda corrente, da perspectiva psicossocial do controle, baseia-se no estudo que as pessoas exercem no exercício do controle organizacional, mas é criticada quanto ao problema de trabalhar com uma visão fragmentada no processo de decisão; e por fim, a terceira corrente, a perspectiva cultural do controle, que embora traga contribuições, sofre críticas de vários autores em relação ao reducionismo que considera a organização (GOMES; SALAS, 2001, p.28; 32-37).

A organização deve ter um sistema de controle gerencial alinhado com as estratégias e metas da empresa. O sistema de controle gerencial deve ser planejado com a finalidade de compatibilizar a responsabilidade de seus gestores com a estrutura organizacional. O sistema de controle gerencial incentiva os empregados e gerentes. Assim, os objetivos individuais se alinham com os objetivos da empresa. Ou seja, as metas estabelecidas pela administração são perseguidas pelos seus funcionários e gerentes (HORNGREN, FOSTER e DATAR, 2000, p. 636-637; HORNGREN, SUNDEM e STRATTON, 2004, p.300).

Para que os objetivos da organização sejam alcançados é necessário que os objetivos individuais de cada membro da empresa estejam alinhados com os objetivos da própria 
organização. Significa dizer que o os atos e atitudes devem estar em conformidade com seus interesses e os interesses da organização (ANTHONY; GOVINDARAJAN, 2006, p. 141).

Buscar harmonizar os interesses particulares com os da organização faz parte do processo de controle gerencial, já que esse controle afeta o comportamento dos indivíduos (ANTHONY; GOVINDARAJAN, 2006, p. 140-141).

O desenvolvimento de uma cultura organizacional que permita aos funcionários uma identificação pode possibilitar que os objetivos da organização sejam congruentes com os objetivos individuais desses funcionários (GOMES; SALAS, 2001, p. 155).

Entretanto, a identificação pode ser reduzida quando existe um sistema burocrático de controle. Essa burocracia, que desmotiva o indivíduo, afasta o comprometimento deste com o sistema de controle, e é manifestada pelos seguintes aspectos: a) limitação ao cumprimento do que está formalizado nos planos e orçamento; b) orientação centrada nos indicadores; c) desperdício de recursos, e d) comportamento centrado no próprio departamento (GOMES; SALAS, 2001, p. 159).

O processo de internalização dos objetivos organizacionais pode ser potencializado pelos seguintes fatores: a) compromisso da organização no processo de controle; b) gerência participativa; c) existência de objetivos claros; d) atitude construtiva e flexível por parte da gerência no planejamento e avaliação de desempenho (GOMES; SALAS, 2001, p. 159).

Anthony e Govindarajan (2006, p. 141) consideram que a congruência dos objetivos é influenciada por fatores informais e que estes fatores se dividem em fatores externos e internos. Para eles, os fatores externos dizem respeito ao padrão de comportamento existente na sociedade na qual a organização está inserida. Já os fatores internos dizem respeito à cultura; estilo de gerenciamento; organização informal; percepção e comunicação; e cooperação e conflito (ANTHONY; GOVINDARAJAN, 2006, p. 142-145).

\subsubsection{O sistema formal de controle}

Assim como os sistemas informais interferem no processo de controle, o sistema formal exerce sua influência (ANTHONY; GOVINDARAJAN, 2006, p. 146).

A estratégia de uma empresa influencia sua estrutura e por sua vez, essa estrutura varia de acordo com o tipo de organização. Basicamente as estruturas podem ser classificadas em três grupos: a) estrutura funcional, onde cada executivo é responsável por uma função específica; b) estrutura de unidade, em que o executivo de cada unidade é responsável pela maioria das atividades dessa unidade; e c) estrutura matricial, onde as unidades funcionais têm dupla responsabilidade (ANTHONY; GOVINDARAJAN, 2006, p. 149).

\subsubsection{Características básicas dos sistemas de controle}

Gomes e Salas (2001, p. 49) chamam a atenção para três aspectos importantes das características dos sistemas de controle. Os aspectos estratégicos como modeladores para o formato do sistema de controle a ser implementado; os aspectos humanos, organizacional e social como importantes instrumentos de controle social e de gestão; e o aspecto da representatividade do sistema de controle no processo de controle.

A informação é um componente significativo no processo de controle, pois permite a formulação dos objetivos e a medição dos resultados. Refere-se a: evolução do contexto social global (tecnológico, sociocultural, político, econômico, demográfico, ecológico); evolução do setor (mercado, competidores, distribuidores, fornecedores, regulamentação da administração pública); e evolução da própria organização (aspectos comerciais, financeiros, produtivos, comportamento individual) (GOMES; SALAS, 2001 p.52).

São informações necessárias à organização para produzir o controle: da contabilidade de custos (o custo de fazer ou não fazer algo); informações de base (serve para o diagnóstico 
gerencial); informações sobre produtividade (comparar o próprio desenho em relação ao que os outros estão fazendo - Benchmarking); informações sobre competência (competências essenciais combinando valor de mercado ao valor do cliente); e informações sobre alocação de recursos (todas as informações que uma gerência tem a respeito do seu negócio). (DRUCKER; 1999, p. 100).

O objetivo dos sistemas de controles é o de facilitar a informação, assim, pode-se avaliar a validade a priori de uma estratégia e sua adequação de implantação. Entretanto, as organizações não usam essas informações de forma estratégica, pois essas informações não são apresentadas de maneira simples, que permita formular estratégias, ou seja, a preferência é dada para as informações qualitativas. (GOMES; SALAS, 2001, p. 115).

O tamanho da empresa afeta diretamente no tipo de controle organizacional e nível de formalização necessário para garantir a delegação de autoridade, para que seja avaliada da forma mais adequada possível. (GOMES; SALAS, 2001, p. 56).

Até muito recentemente, as organizações desenvolviam-se em contextos sociais estáveis, nos quais o processo de decisão era muito simples. Isso não exigia instrumentos de controles sofisticados e bom grau de formalização. As organizações atuais enfrentam cada vez mais graus de incertezas. A imprevisibilidade e a continuidade das mudanças no contexto social e a crescente complexidade das atividades seriam os principais motivos.

Isto impacta diretamente os sistemas de controle das organizações. A utilização de um sistema de controle requer o desenho da estrutura de controle e a realização do processo de controle. No Quadro 2 apresentam-se os tipos de sistemas de controle.

\begin{tabular}{|c|c|c|c|}
\hline Conceito & Controle estratégico & Controle orçamentário & Controle operacional \\
\hline Horizonte temporal & Longo prazo & $\begin{array}{l}1 \text { ano - orçamento e } \\
\text { mensal (desvios) }\end{array}$ & Diário semanal \\
\hline Finalidade & $\begin{array}{l}\text { Fixar e avaliar objetivos e } \\
\text { estratégias. } \\
\text { Facilitar a adaptação ao } \\
\text { meio ambiente e } \\
\text { promover melhora } \\
\text { contínua da posição } \\
\text { competitiva }\end{array}$ & $\begin{array}{l}\text { Fixar e avaliar metas e } \\
\text { políticas a curto prazo. } \\
\text { Facilitar a } \\
\text { descentralização e agilizar } \\
\text { os recursos para alcançar } \\
\text { as metas e avaliar a } \\
\text { atuação }\end{array}$ & $\begin{array}{l}\text { Fixar e avaliar } \\
\text { procedimentos operacionais. } \\
\text { Influenciar o } \\
\text { comportamento para } \\
\text { motivar a melhora contínua. }\end{array}$ \\
\hline Nível de hierarquia & $\begin{array}{l}\text { Diretoria e gerentes de } \\
\text { unidades de negócio. }\end{array}$ & $\begin{array}{l}\text { Gerentes de unidade de } \\
\text { negócios e de } \\
\text { departamentos. }\end{array}$ & $\begin{array}{l}\text { Supervisores, Departamento } \\
\text { setor, seção. }\end{array}$ \\
\hline Complexidade & $\begin{array}{l}\text { Elevada. } \\
\text { Grande número de } \\
\text { variáveis internas e } \\
\text { externas. }\end{array}$ & Moderada & Pequena \\
\hline $\begin{array}{l}\text { Atividade a } \\
\text { controlar }\end{array}$ & $\begin{array}{l}\text { Posição competitiva } \\
\text { global e por unidades. }\end{array}$ & Desvios do orçamento & $\begin{array}{l}\text { Padrão técnico. } \\
\text { Operacional. }\end{array}$ \\
\hline Ponto de partida & $\begin{array}{l}\text { Análise do meio ambiente } \\
\text { e da organização. }\end{array}$ & Planejamento estratégico. & Metas operacionais. \\
\hline Conteúdo & $\begin{array}{l}\text { Amplo, geral e } \\
\text { quantitativo, variáveis não } \\
\text { financeiras. }\end{array}$ & $\begin{array}{l}\text { Específico, detalhado, } \\
\text { medidas financeiras. }\end{array}$ & Repetitivo, dados físicos. \\
\hline Informação & $\begin{array}{l}\text { Externa e interna. } \\
\text { Intuitiva, semi confusa. }\end{array}$ & $\begin{array}{l}\text { Interna, financeira } \\
\text { precisa. }\end{array}$ & $\begin{array}{l}\text { Interna, técnica. } \\
\text { Grande precisão. }\end{array}$ \\
\hline Grau de predição & Muito baixo. & Alto. & Muito alto. \\
\hline $\begin{array}{l}\text { Estrutura de } \\
\text { decisão }\end{array}$ & $\begin{array}{l}\text { Não programadas, } \\
\text { imprevisíveis. }\end{array}$ & Pouco estruturadas. & Muito estruturado. \\
\hline
\end{tabular}

Quadro 2 - Tipos de sistemas de controle

Fonte: Gomes e Salas (2001, p.114). 
O Quadro 2 apresenta os três tipos de controle (estratégico, orçamentário e operacional) e mostra as principais diferenças para cada tipo de controle.

Gomes e Salas (2001, p. 57-60) apresentam como tipos de controles organizacionais o:

a) Controle familiar: muito ligado às características do líder, encontrado em empresas pequenas, não é necessariamente familiar e sim suas características são familiar. Ambiente social estável e pouco hostil. Controles informais;

b) Controle ad-hoc: típico de ambientes muito dinâmicos e de grande complexidade, com estrutura bastante descentralizada, esse tipo de controle baseia-se na utilização de elementos não formais que ajudam no controle;

c) Controle burocrático: típico de ambientes pouco competitivos e empresas grandes. Estrutura centralizada, contexto social pouco hostil e pouco dinâmico, elevada formalização e a delegação ocorrem para pessoas de alta confiança;

d) Controle por resultados: Costuma existir em ambientes sociais muito competitivos. Esse tipo de controle se aproxima muito do controle burocrático, sua principal diferença está no controle financeiro que é mais abrangente.

\subsubsection{Desenho da estrutura de controle de gestão}

Segundo Gomes e Salas (2001, p. 73),

O desenho da estrutura de controle tem implicações tanto no desenho do quadro de indicadores de controle que possibilita o controle por exceção de cada unidade e medida de atuação, como no desenho do sistema de informação que possibilita a medição do desempenho e o acompanhamento periódico da evolução dos indicadores anteriores.

Na Figura 1 apresenta-se o desenho dos elementos dos sistemas de controles conforme Gomes e Salas (2001, p. 73).
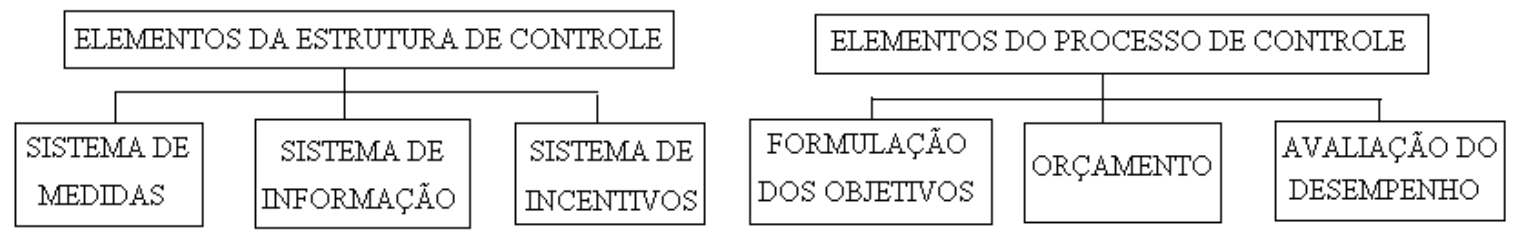

Figura 1 - Desenho dos elementos dos sistemas de controles Fonte: adaptado de Gomes e Salas (2001, p. 54).

Para se avaliar um sistema de controle é preciso analisar os aspectos culturais e o contexto em que a empresa está inserida. Isto acontece em função das diferenças existentes em cada organização e das diferenças regionais e históricas. Esta análise é feita sob diversas perspectivas: contingencial (seu desenho depende do tamanho da empresa, tecnologia, nível de concorrência etc.); relações humanas (concentração no grau de participação existente ou no impacto motivacional que produz); política (o sistema de controle sofre reflexos de lutas políticas internas e externas à organização); e cultural (o sistema de controle como elemento criador de valores na organização) (GOMES; SALAS, 2001, p. 53).

No desenho da estrutura de controle são encontrados alguns elementos: a) os indicadores tradicionais (indicadores de rentabilidade, indicadores de financiamento e indicadores de investimentos) possibilitam uma comparação entre o objetivo inicial e o alcançado pela organização, bem como os motivos que favorecem ou dificultam o alcance dos objetivos; b) quadro de indicadores (rentabilidade do capital, endividamento, rotação dos estoques, expansão comercial, liderança comercial, êxito na inovação, satisfação dos clientes 
e clima de trabalho) são informações adicionais aos indicadores financeiros; e c) indicadores de benchmarking (análise interna comparada com os principais competidores) (GOMES; SALAS; 2001 p.74-76).

\subsubsection{Centros de responsabilidade}

"Um centro de responsabilidade é uma unidade da organização sob supervisão de um executivo por suas atividades" (ANTHONY; GOVINDARAJAN, 2006, p. 180). Para o autor a finalidade dos centros de responsabilidade é ajudar a organização a implementar suas estratégias. "Se as estratégias forem sadias e se cada centro de responsabilidade atinge seus objetivos, a própria empresa atinge suas metas" (ANTHONY; GOVINDARAJAN; 2006 p. 181).

Os critérios adotados para avaliar o desempenho dos centros de responsabilidade são a eficiência e eficácia. "[...] um centro de responsabilidade é eficiente quando faz corretamente as coisas, e eficaz quando faz as coisas certas" (ANTHONY; GOVINDARAJAN; 2006 p. 184).

O Quadro 3 apresenta as características dos centros de responsabilidade. Nos centros de receitas somente as saídas são avaliados em termos monetários. Já nos centros de despesas, as entradas é que são avaliadas em termos monetários. Nos centros de lucros, são avaliadas em termos monetários as receitas e despesas. Nos centros de investimento, o que é avaliado é a relação entre investimento e lucro (ANTHONY; GOVINDARAJAN, 2006, p. 184).

\begin{tabular}{|l|l|l|}
\hline \multicolumn{1}{|c|}{ Tipo } & \multicolumn{1}{|c|}{ Características } & \multicolumn{1}{c|}{ Função } \\
\hline $\begin{array}{l}\text { Centros de despesas } \\
\text { disciplinados }\end{array}$ & $\begin{array}{l}\text { Entradas avaliadas em termos monetários. } \\
\text { Saídas avaliadas em quantidades físicas. } \\
\text { Pode ser determinado o valor necessário para produzir uma } \\
\text { unidade de saída. }\end{array}$ & De produção \\
\hline $\begin{array}{l}\text { Centros de despesas } \\
\text { discricionários }\end{array}$ & $\begin{array}{l}\text { Incluem setores administrativos e de apoio, pesquisa e } \\
\text { desenvolvimento e a maioria das atividades de marketing. } \\
\text { Adoção de políticas que balizam as operações da empresa. } \\
\text { A diferença entre despesas reais e despesas orçadas não é um } \\
\text { parâmetro de avaliação da eficiência de um centro de despesas } \\
\text { discricionário }\end{array}$ & $\begin{array}{l}\text { De pesquisa e } \\
\text { desenvolvimento }\end{array}$ \\
\hline Centros de receitas & As entradas não têm relação com as saídas. & De marketing \\
\hline Centros de lucros & Entradas têm relação com as saídas. & Unidade operacional \\
\hline $\begin{array}{l}\text { Centros de } \\
\text { investimento }\end{array}$ & Os lucros têm relação com o capital investido. & Unidade operacional \\
\hline
\end{tabular}

Quadro 3 - Tipos de centros de responsabilidade

Fonte: adaptado de Anthony e Govindarajan (2006, p. 185).

\subsubsection{Emergência do controle estratégico}

Gomes e Salas (2001, p. 107) falam da importância das organizações em ter estratégias que lhes permita uma adaptação com o meio ambiente, a fim de adequarem as operações internas às exigências do ambiente em que estão inseridas, onde suas estratégias e estrutura organizacional é que vão permitir que a empresa possa aproveitar as oportunidades de forma mais conveniente.

Quanto maior for a turbulência do contexto social e mais aguerrida a concorrência, mais importante se torna que os sistemas de controle disponham de mecanismos que sejam sensíveis a este contexto e aos aspectos ligados à competitividade.

A formulação da estratégia permite determinar metas específicas para cada um dos centros de responsabilidade, de modo que cada um dos componentes tome decisões coerentes com os objetivos acordados entre os diversos membros da organização [...] (GOMES; SALAS, 2001, p. 107-108). 


\subsubsection{Vinculação do sistema de controle com o contexto organizacional}

O novo modelo de gestão inclui uma ampla participação de todos dentro de uma organização e fora dela, desde os empregados até fornecedores e governo. Com isso, pode-se direcionar o foco nas necessidades dos clientes através de planos, programas e orçamentos. Mecanismos formais e não-formais podem ser utilizados, mas devem ser coerentes com a cultura, estrutura, liderança e valores interpessoais das organizações, e também devem ser considerados os aspectos do contexto social e competitivo. (GOMES; SALAS, 2001, p. 126).

A estrutura organizacional deve ser facilitadora para que diferentes atividades sejam realizadas. A complexidade da atividade e a incerteza promovem a discricionariedade e uma difícil formalização. Alta descentralização torna difícil e caro o controle, o que pode justificar a preferência pela centralização. Uma empresa que seja descentralizada exige que seu sistema de controle sofisticado e formalizado. (GOMES; SALAS, 2001, p. 127).

O sistema de controle de uma estrutura centralizada é pouco sofisticado, seus mecanismos são informais e suas normas rígidas. Os indicadores de controle são em regra qualitativos e nem sempre orientados a resultados. O seu sistema de informação é orientado para o resultado global e pouco orientado ao controle de responsabilidades. O processo de planejamento é inexistente ou intuitivo (seu sistema de avaliação é baseado em informação não financeira).

Já o sistema de controle de uma estrutura descentralizada deve ser muito sofisticado com mecanismos formais e controle financeiro. Os indicadores de controle são também qualitativos, porém orientados para resultados. O sistema de informação é orientado para o processo de tomada de decisão e para o controle do desempenho dos responsáveis. O processo de planejamento é importante para o alcance dos objetivos globais. E seu sistema de avaliação baseia-se tanto em informação não financeira quanto financeira (GOMES; SALAS, 2001, p. 128).

\footnotetext{
Como em toda organização com diferentes unidades descentralizadas é normal que se estabeleçam relações comerciais entre os diferentes centros através da compra e venda de serviços que se realizam entre eles e porque estas relações podem afetar a atuação e o resultado obtido por determinado centro, é necessário estabelecer os mecanismos de coordenação para que as diferentes unidades não somente otimizem seus objetivos financeiros e não financeiros específicos, como também atuem de acordo com os objetivos globais da organização. (GOMES; SALAS, 2001, p. 131).
}

Existem alguns mecanismos que ajudam na coordenação entre as distintas unidades organizacionais.

a) mecanismos culturais: os valores da organização e sua cultura influenciam nas relações existentes e na forma como se realizam;

b) mecanismos burocráticos: as normas e procedimentos são claramente bem definidos para todos;

c) preços de transferência: uma forma de incentivo bastante utilizada em empresas com sistemas mais sofisticados (GOMES; SALAS, 2001, p.131).

\subsubsection{Centros de lucro}

Centro de lucro é um centro de responsabilidade que a partir do momento em que haja uma avaliação de desempenho do centro de responsabilidade pelo lucro auferido, este passa a ser denominado como centro de lucro (ANTHONY; GOVINDARAJAN, 2006, p. 226). Nos centros de lucro as receitas e os custos dos serviços ou produtos que são produzidos são controlados pelos funcionários e gerentes (ATKINSON et al., 2000, p. 625). O Princípio da Contrabilidade deve ser aplicado aos centros de responsabilidade. Isto implica dizer que a 
responsabilidade do gerente do centro deve fica limitada aos custos, receitas ou investimentos que o mesmo controla, ou seja, um gerente não deve ser responsabilizado por fatores que ele não controla (ATKINSON et al., 2000, p. 626).

A contabilidade por responsabilidade ou Contabilidade Divisional, engloba uma série de conceitos de contabilidade gerencial, os quais permitem que haja para os gestores das unidades de negócios condições para mensuração, identificação, acumulação informação e decisão de cada um dos gestores (PADOVEZE, 2004, p. 258).

As empresas decidem criar centros de responsabilidades para que possa ser delegada mais autoridade aos gestores operacionais (ANTHONY; GOVINDARAJAN, 2006, p. 227).

$\mathrm{O}$ resultado apurado nas unidades divisionais permite avaliar o desempenho dos gestores. Ao atribuir responsabilidade por resultado, quer seja positivo ou negativo, ao gestor de cada unidade, as organizações buscam a minimização do repasse de eficiências ou ineficiências entre as unidades de negócios. (JUNQUEIRA; MORAES, 2005, p. 38-39).

Para Anthony e Govindarajan (2006, p. 227) a avaliação de desempenho utilizando como parâmetro o centro de lucro é acertiva, pois possibilita à administração a adoção de uma medida universal.

\title{
2.1.8 Preços de transferência
}

O preço de transferência é o mecanismo que permite a distribuição da receita, quando dois ou mais centros de lucro são de forma conjunta responsáveis pelo desenvolvimento de determinado produto. O preço de transferência é uma ferramenta contábil que motiva os gestores para uma decisão correta (ANTHONY; GOVINDARAJAN, 2006, p. 271). Para os autores o preço de transferência deve cumprir os seguintes objetivos: a) permitir a informação relevante; b) induzir para decisões que tenham congruência de objetivos; c) contribuir parar a avaliação do desempenho econômico de todos os centros de lucros; e d) ser simples de entender e fácil de administrar. Já Hansen e Mowen (2003, p. 334) apontam como objetivos do preço de transferência: uma acurada avaliação de desempenho, os objetivos serem congruentes e ter a autonomia divisional preservada.

Ao adotar o preço de transferência, a empresa deve ter cuidado na sua definição. Sua utilização serve para que os lucros possam ser aumentados. Entretanto, o uso inadequado do preço de transferência pode diminuir o lucro da empresa (WARREN; REEVE; FESS, 2001, p.282).

\subsubsection{Planejamento estratégico e o Balanced Scorecard (BSC)}

De acordo com Anthony e Govindarajan (2006, p. 271),

\begin{abstract}
Uma razão importante para separar na prática a formulação de estratégias do planejamento estratégico é o fato de que este último tende a se tornar institucionalizado, e essa tendência inibe atividades puramente criativas. A segregação da formulação de estratégias como atividade separada (...) pode eliminar essa tendência. A formulação de estratégias é uma atividade em que a criatividade e a inovação devem fortemente ser encorajadas.
\end{abstract}

O planejamento estratégico segue um rito. Na etapa de formulação da estratégia são definidos os objetivos da empresa e a estratégia a ser implementada, a fim de que os objetivos possam ser atingidos. No processo de planejamento estratégico busca-se desenvolver programas de trabalhos para o cumprimento das estratégias adotadas (ANTHONY; GOVINDARAJAN, 2006, p. 382). 


\subsubsection{Natureza do planejamento estratégico}

Para Anthony e Govindarajan (2006, p. 384-385) um processo formal de planejamento traz algumas vantagens para a empresa:

a) estrutura para a elaboração do orçamento anual - o planejamento estratégico permite uma melhor alocação de recursos, ele deve ser feito baseado no entendimento do direcionamento da empresa a ser adotado nos anos subseqüentes;

b) instrumento de aperfeiçoamento de executivos - ao induzir os executivos a pensar em estratégias e sua implementação, o planejamento estratégico permite o aprimoramento dos executivos;

c) mecanismo para levar os executivos com as estratégias da empresa - o planejamento estratégico leva os indivíduos a pensarem no longo prazo, dando ênfase aos assuntos mais importantes;

d) alinhamento dos executivos com as estratégias da empresa - as discussões e as negociações em torno do planejamento estratégico permitem que haja uma troca de informações entre os executivos e aponta as implicações das estratégias em cada um deles;

e) definição de providências a curto prazo - o planejamento estratégico mostra as implicações da programação de decisões a curto prazo

\subsubsection{Controle para estratégias diferenciadas e Balanced Scorecard}

A estratégia de uma organização descreve como ela pretende criar valor para seus acionistas, clientes e cidadãos. (KAPLAN; NORTON, 2004, p. 5).

Para Kaplan e Norton (2004, p. 5), o Balanced Scorecard é uma poderosa ferramenta gerencial. Entretanto, para que os sistemas de mensuração exerçam o maior impacto possível, eles devem concentrar-se na estratégia da organização - como ela espera criar valor sustentável no futuro. Ao projetar o Balanced Scorecard, a organização deve medir os poucos parâmetros críticos que representam sua estratégia para a criação de valor a longo prazo.

O Balanced Scorecard (BSC) constitui um sistema de gestão estratégica capaz de subsidiar os gestores com informação relevante para a realização das estratégias empresariais, incluindo a relativa aos ativos intangíveis, ou seja, pessoas, procedimentos organizacionais e tecnologia, que constituem a chave da criação de valor aos clientes, acionistas, empregados e sociedade. Ele combina tradicionais indicadores financeiros, com medições não financeiras para medir a saúde da companhia em quatro perspectivas, conforme Quadro 4.

\begin{tabular}{|l|l|}
\hline Financeira & $\begin{array}{l}\text { mede o impacto econômico das ações, em indicadores de crescimento, lucratividade e } \\
\text { risco dos shareholders (ROI, ROA...) }\end{array}$ \\
\hline Clientes & $\begin{array}{l}\text { mede a capacidade da organização em gerar produtos e serviços de qualidade que } \\
\text { satisfaçam as necessidades dos clientes (retenção de clientes, market-share, } \\
\text { lucratividade, satisfação, lealdade...). }\end{array}$ \\
\hline Processos internos & $\begin{array}{l}\text { mede os processos internos que criam satisfação aos clientes e shareholders } \\
\text { (qualidade, tempo de resposta...) }\end{array}$ \\
\hline Desenvolvimento & $\begin{array}{l}\text { mede o ambiente organizacional que viabiliza mudança, inovação, compartilhamento } \\
\text { de informações e crescimento (clima organizacional, treinamento, conhecimento } \\
\text { compartilhado...). }\end{array}$ \\
\hline
\end{tabular}

Quadro 4 - Perspectivas utilizadas na análise do BSC

Fonte: adaptado de Kaplan e Norton (2004, p. 5).

Embora o foco de cada perspectiva seja diferente, existe uma relação de causalidade que une as quatro perspectivas. Se por exemplo, uma companhia investe em treinamento para melhorar as habilidades dos funcionários, então estes resultados gerarão impacto nos processos internos, melhorando sua qualidade. Estas atividades, por conseguinte, irão resultar em produtos de qualidade superior, com conseqüentes melhores resultados financeiros e 
melhor satisfação do cliente (CARVALHO; SANTOS, 2009).

Um ponto relevante a se considerar no BSC é que, normalmente medidas financeiras, embora importantes, descrevem o que aconteceu no passado, no mês passado ou no ano passado. Entretanto, medindo a desempenho da perspectiva do cliente, dos processos internos e da perspectiva de desenvolvimento em uma base temporal mais próxima, é possível estar à frente dos números, criando um ambiente de prevenção e não de reação (CROSS, 2004).

Para Kaplan e Norton (2004, p. 7) o Balanced Scorecard oferece exatamente um modelo para descrição de estratégias que criam valor. O modelo BSC contém vários elementos importantes:

a) $\mathrm{O}$ desempenho financeiro, indicador de resultado (lag indicator), é o critério definitivo do sucesso da organização. A estratégia descreve como a organização pretende promover o crescimento de valor sustentável para os acionistas.

b) O sucesso com os clientes-alvo é o principal componente da melhora do desempenho financeiro. Além de medir através de indicadores de resultado como satisfação, retenção e crescimento o sucesso com os clientes é o elemento central da estratégia.

c) Os processos internos criam e cumprem a proposição de valor sustentável. Os objetivos de aprendizado e crescimento descrevem como pessoas, tecnologia e clima organizacional se conjugam para sustentar a estratégia. As melhorias nos resultados de aprendizado e crescimento são indicadores de tendência para os processos internos, clientes e desempenho financeiro.

d) Os objetivos das quatro perspectivas interligam-se uns como os outros numa cadeia de relação de causa e efeito. O desenvolvimento e o alinhamento dos ativos intangíveis induzem as melhorias no desempenho dos processos, que, por sua vez, impulsionam o sucesso para os clientes e acionistas.

\subsubsection{Estratégia empresarial}

As empresas que têm apenas uma atividade tendem a ser organizadas funcionalmente, com a alta administração responsável pela determinação de sua estratégia central para competir dentro de suas estratégias funcionais, em áreas como pesquisa e desenvolvimento, produção e marketing (ANTHONY; GOVINDARAJAN 2006, p. 692).

Os conglomerados com diversificação em vários ramos são organizados em unidades relativamente autônomas. A alta administração dessas empresas tende a concentrar-se no gerenciamento de portfólio (na seleção das operações para as quais devem ser designados recursos financeiros, nas várias unidades), e delega a formulação de estratégias de produção e de marketing aos executivos das unidades (ANTHONY; GOVINDARAJAN 2006, p. 692).

Ao evoluir de uma única atividade para atividades diversificadas em vários ramos, a autonomia dos executivos das unidades tende a aumentar, por duas razões. Em primeiro lugar, os membros da alta administração de empresas com atividades diversificadas em vários ramos podem não ter o conhecimento e a especialização necessários para tomar decisões estratégicas e operacionais para grupos de unidades díspares. Em segundo lugar, há muito pouca interdependência entres as unidades de um conglomerado, assim como pode existir grande interdependência entre unidades de uma empresa de uma única atividade; maior interdependência acarreta maior intervenção da alta administração (ANTHONY; GOVINDARAJAN, 2006, p. 693).

A adoção de estratégias de forma eficaz não pode estar dissociada de um sistema consistente de controle gerencial. As relações de subordinação, a responsabilidade e a autoridade dos executivos são definidas pela estrutura organizacional, entretanto seu funcionamento depende de um apropriado sistema de controle (ANTHONY; GOVINDARAJAN, 2006, p. 694). 


\subsection{O processo de internacionalização das empresas}

Tradicionalmente, a internacionalização tem sido vista como uma forma de aumentar a rotatividade das empresas. Exportar é o caminho tradicional da internacionalização, e continua importante, mas na última década, a internacionalização tem se tornado um diferencial e de crucial importância para a competitividade das empresas.

Parcerias estrangeiras, investimentos estrangeiros e agrupamentos internacionais representam caminhos viáveis para facilitar o intercâmbio do conhecimento e das estratégias empresariais internacionais. Atividades de internacionalização acontecem nos dois sentidos ao longo da cadeia de valor (de dentro para fora e de fora para dentro).

Existem duas etapas na internacionalização, a primeira delas é quando a empresa só exporta os seus serviços ou produtos, e a segunda é quando a empresa de alguma forma já está baseada no exterior (representações, distribuição e até mesmo instalação de um chão de fábrica) (ALEM; CAVALCANTI, 2005).

Está evidenciado que a economia mundial já não é única ou um número limitado de centros e periferias. Embora a economia global não seja distribuída de forma uniforme, ela se tornou uma estrutura complexa do processo produtivo, em que os produtos já não são mais fabricados em um único país e sim em uma cadeia de produção internacional. Exemplos são encontrados nos setores de desporto, móveis, telefones, carros, roupas, computadores, etc. (JONES; KIERZOWSKI, 2004, p. 4).

De acordo com o Boletim Sobeet (2007), acerca do processo de internacionalização das empresas, houve um aumento acumulado de US\$ 35,1 bilhões, de setembro de 2006 a setembro de 2007, do fluxo de Investimentos Diretos Estrangeiros. O que chama atenção no Boletim é o fato do Investimento Brasileiro Direto ter sido, no mesmo período, de US\$27,2 bilhões, repercutindo no processo de internacionalização das empresas.

$\mathrm{O}$ investimento estrangeiro direto reflete o objetivo de se obter um interesse duradouro por uma empresa a partir de uma (fonte) em outro país (host) país. O interesse duradouro implica a existência de uma relação de longo prazo entre o investidor direto e a empresa e um significante grau de influência sobre a gestão (IEP Paris, 2007).

Para se qualificar como IDE, o investimento deverá permitir à controladora o controle sobre suas filiais estrangeiras. Possuir $10 \%$ ou mais do capital social ou poder de voto (IEP Paris, 2007). A controladora e filial ou subsidiária estrangeira formam, em conjunto, uma empresa multinacional (MNE) ou Transnational Corporation (TNC) (IEP Paris, 2007).

$\mathrm{O}$ investimento direto envolve tanto a transação inicial entre as duas entidades e as subseqüentes transações de capital entre eles e entre empresas filiais, tanto incorporadas como não incorporada (IEP Paris, 2007).

\begin{tabular}{|l|l|}
\hline $\begin{array}{l}\text { Green vs } \\
\text { Brown }\end{array}$ & $\begin{array}{l}\text { Investimento Greenfield é o investimento em uma nova instalação ou nova planta, criando uma } \\
\text { nova capacidade de produção. } \\
\text { Investimento Brown é investimento oposto, é a compra de uma fábrica já existente ou empresa }\end{array}$ \\
\hline $\begin{array}{l}\text { Fusões e } \\
\text { Aquisições }\end{array}$ & $\begin{array}{l}\text { Fusões e aquisições são os principais tipos de IDE. A fusão trans-fronteiriça ocorre quando os } \\
\text { ativos e operações das duas empresas (nos dois países) são combinados para criar uma nova } \\
\text { entidade jurídica. Uma aquisição ocorre quando o controle de ativos e operações é transferido } \\
\text { de uma empresa local para uma empresa estrangeira. }\end{array}$ \\
\hline $\begin{array}{l}\text { Investimento na vertical, uma empresa investe em diferentes processos de entrada em diversos } \\
\text { países. } \\
\text { hortical } \\
\text { vs IDE }\end{array}$ & $\begin{array}{l}\text { IED vertical ocorre quando uma indústria no estrangeiro fornece insumos para a produção } \\
\text { IED vertical ocorre também quando uma indústria vende no exterior as saídas do processo de } \\
\text { produção de uma empresa nacional. } \\
\text { Investimento na horizontal é o investimento na mesma indústria no exterior. }\end{array}$ \\
\hline
\end{tabular}

Quadro 5 - Tipos de investimento direto estrangeiro

Fonte: IEP Paris (2007). 
O Quadro 5 apresenta os tipos de investimento direto estrangeiro. Amal e Seabra (2007, p. 234) propõem que o IDE seja classificado em quatro tipos principais de projetos. O market-seeking projects que são aqueles projetos de investimento cujo objetivo é atender o mercado interno dos países que recebem o IDE; o segundo, efficiency-seeking projects que são os investimentos que procuram uma redução dos custos de produção, estes projetos têm foco tanto no mercado interno como no externo; o terceiro, o resource-seeking projects em que o foco é o acesso melhor às matérias-primas e à mão-de-obra com custos menores; e, por último, o asset-seeking projects que são aqueles em que são obtidos pela instalação de novas fábricas, fusões, aquisições ou operações de joint ventures.

De acordo com o que foi exposto, pode-se perceber que existe uma fragmentação da produção das empresas. Essa fragmentação da produção mundial refere-se à divisão do processo de produção integrada anteriormente em dois ou mais componentes, ou "fragmentos". Ela é possibilitada pela utilização de atividades do setor dos serviços e resulta em um realinhamento de padrões de produção entre os países e um aumento do comércio intra-empresa (IEP Paris, 2007). O IEP aponta diversas causas da fragmentação da produção: economias de escala, maior concorrência, maior eficiência, progresso tecnológico no setor de serviços, diferenças entres as políticas (ex: política fiscal), etc.

A questão da aglomeração das atividades econômicas ou seu oposto poderia ser pensado como exigindo um modelo novo de explicação. Não é evidente, contudo, que há algumas provas empíricas esmagadoras que demonstram tendências claras quanto à aglomeração ou desaglomeração, em um ambiente nacional, regional ou global. (JONES; KIERZOKWSKI, 2004).

\section{PROCEDIMENTOS METODOLÓGICOS}

O paradigma adotado para a pesquisa foi o fenomenológico, pois sua realidade pode ser considerada como subjetiva e múltipla. $\mathrm{O}$ interesse de entendimento da pesquisa foi $\mathrm{o}$ comportamento humano (COLISS; HUSSEY, 2005, p. 54; 55-59). O paradigma fenomenológico costuma produzir dados qualitativos e utiliza-se de pequenas amostras (COLLIS; HUSSEY, 2005, p. 61).

A pesquisa pode ser classificada como um estudo de caso descritivo, já que foi realizado um exame extensivo de uma única empresa (metodologia fenomenológica) e descreve a prática corrente. Seu foco de estudo foi uma única unidade de análise. (COLLIS; HUSSEY, 2005, p. 72-73).

O objetivo da pesquisa foi explorar as características do controle gerencial da empresa estudada, além de tentar entendê-lo dentro do contexto de internacionalização de empresas brasileiras (COLLIS; HUSSEY, 2005, p. 73).

Para realizar o trabalho, foi feito em um primeiro momento uma pesquisa bibliográfica, acerca de controle gerencial, em livros, periódicos, teses, dissertações e internet. Procuraram-se tratar no presente trabalho, de forma detalhada, as principais teorias existentes sobre controle gerencial, na intenção de se verificar o grau de proximidade e afastamento existente entre a literatura e o que foi identificado na empresa estudada.

A escolha da empresa foi feita através do site do Portal do Exportador na internet, onde foi feito um contato inicial com o responsável pelo setor de exportação da empresa estudada. Buscaram-se informações, através de um estudo de caso na empresa do ramo de material elétrico, sobre as características do sistema de controle gerencial em empresas internacionalizadas. Nesta etapa do trabalho foram feitos contatos com a empresa

Ainda nesta fase, buscou-se selecionar as pessoas a serem entrevistadas. Foram escolhidos profissionais das principais áreas da empresa que possuem algum envolvimento com o controle gerencial 
Em seguida realizou-se análise documental e entrevistas informais e semi-estruturadas com as pessoas previamente selecionadas. Os participantes selecionados fazem parte do quadro de funcionários e da alta administração da empresa.

Através dos dados levantados, realizou-se a análise dos mesmos para determinar respostas ao problema de pesquisa. O estudo de caso se desenvolveu na matriz da empresa que fica situada no Estado do Rio de Janeiro.

\section{O CASO DA EMPRESA DO RAMO DE MATERIAL ELÉTRICO}

\subsection{Principais características da empresa}

Empresa 100\% brasileira, criada em 1972. Sua matriz é no Rio de Janeiro, tendo uma filial no Estado de São Paulo. Atua no setor industrial de material elétrico nos seus múltiplos segmentos. Produz chaves eletromecânicas para aplicação em baixa tensão, até 690 volts. Tais dispositivos são utilizados em máquinas e painéis elétricos como elementos de chaveamento, estabelecendo ou interrompendo a circulação de corrente elétrica pelo circuito ao qual estejam ligados. As vantagens dos seus produtos são: robustez e preço competitivo. A principal desvantagem desses produtos é a restrição de sua aplicação. Isto se justifica pelo fato de não ter tecnologia de ponta e, em alguns casos, por seus aspectos dimensionais.

\subsection{Posicionamento da empresa no mercado}

O mercado consumidor nacional tem como característica a aceitação de produtos de diferentes níveis de qualidade e preço. A concorrência é bastante acirrada em função de não exigir tecnologia nova em sua fabricação e pela inundação do mercado por produtos de origem chinesa.

Com relação aos fabricantes de chaves eletromecânicas existem dois grupos: os que fabricam chaves rotativas (Rotary Cam Switches) e os que fabricam as chaves seccionadoras (Switch Disconnectors).

O principal fabricante mundial de chaves rotativas é a empresa austríaca Kraus Naimer, que tem fábrica no Brasil, além de unidades nos Estados Unidos, na Europa e na Oceania. Existe no Brasil ainda a norte-americana Cutler-Hammer, que também tem fábrica no Brasil. Fabricantes nacionais, como Steck, THS, Mar-Girius, Lombard, também disputam o mercado, oferecendo, porém, um leque menor de opções de tipos de chave, com qualidade inferior. Há ainda empresas estabelecidas no Brasil que importam chaves do mesmo tipo para comercializá-las no país. Como exemplo, pode ser citado a ACE-Schmersal, além das grandes empresas como Schneider (francesa), GE (norte-americana), ABB (suiça). A Siemens (alemã) é uma empresa que adquire as chaves rotativas que vende no Brasil da fábrica brasileira da Kraus Naimer.

Com relação às chaves seccionadoras para baixa tensão, o maior fabricante brasileiro é a Holec. Suas chaves são fornecidas à Siemens, que as comercializa. Outros fabricantes locais são Schak, Begin, TEE. As chaves seccionadoras que são importadas são fabricadas pela Asea Brown Bovery (ABB) e também por fabricantes chineses.

\subsection{O processo de internacionalização da empresa}

O processo de internacionalização da empresa foi conseqüência de um contrato de parceria com uma grande empresa do setor.

Atualmente a exportação da empresa está restrita ao mercado sul-americano e as vendas são para reposição e em casos muito especiais, a experiência de exportação da empresa está restrita ao mercado sul-americano. 
Nos anos 80, quando se deu o contrato de parceria, as vendas da empresas estavam bastante alavancadas. Com o encerramento do contrato de parceira ocorrido há muitos anos, a empresa começou a perder mercado. Não houveram por parte da empresa tentativas nem de conquistar novos mercados nem de manutenção de mercado já existente no fora do país. Com isto, a participação dos produtos fabricados pela empresa no mercado latino se reduziu substancialmente, restando hoje poucos negócios anuais e de baixo valor.

\subsection{Estratégias da empresa e seu organograma}

Dentro de seu segmento, as chaves são produtos de consumo. Existe demanda de mercado em virtude da produção de máquinas eletromecânicas e da instalação de painéis elétricos de baixa tensão, mais ou menos complexos, presentes em todas as instalações que usem energia elétrica. Produzem para atender encomendas, seja dos fabricantes das máquinas e de painéis elétricos, seja dos distribuidores interessados em comercializar os seus produtos. O esforço atual da empresa está direcionado em localizar os potenciais clientes e em manter os já conquistados.

Na fábrica estão os operários, que aguardam os pedidos para produzir. Esses pedidos são encaminhados à fabrica pelo departamento de vendas, representada por um escritório localizado em São Paulo e por representantes espalhados pelo país.

Os vendedores são comissionados, embora seus ganhos não advenham somente de comissões. Assim, o sucesso deles depende do desempenho das vendas.

A empresa não pensa em reavaliar estratégias. $\mathrm{Na}$ verdade não existe um planejamento estratégico propriamente dito. Todas as decisões então centralizadas em seus diretores. O seu planejamento estratégico é feito pela alta direção da empresa.

O organograma da empresa é apresentado da seguinte forma: a) Direção Geral supervisiona através de responsáveis setoriais (gerentes ou chefes) os setores de: Vendas, Contas a Receber, Contas a Pagar, Área Fiscal, Recursos Humanos e Compras; b) Diretoria Industrial - supervisiona através de responsáveis (gerente ou supervisores) os setores de: Produção; Almoxarifados de matéria-prima e de componentes; Controle de qualidade; Manutenção; e Compras. Na Figura 2 apresenta-se o organograma da empresa.

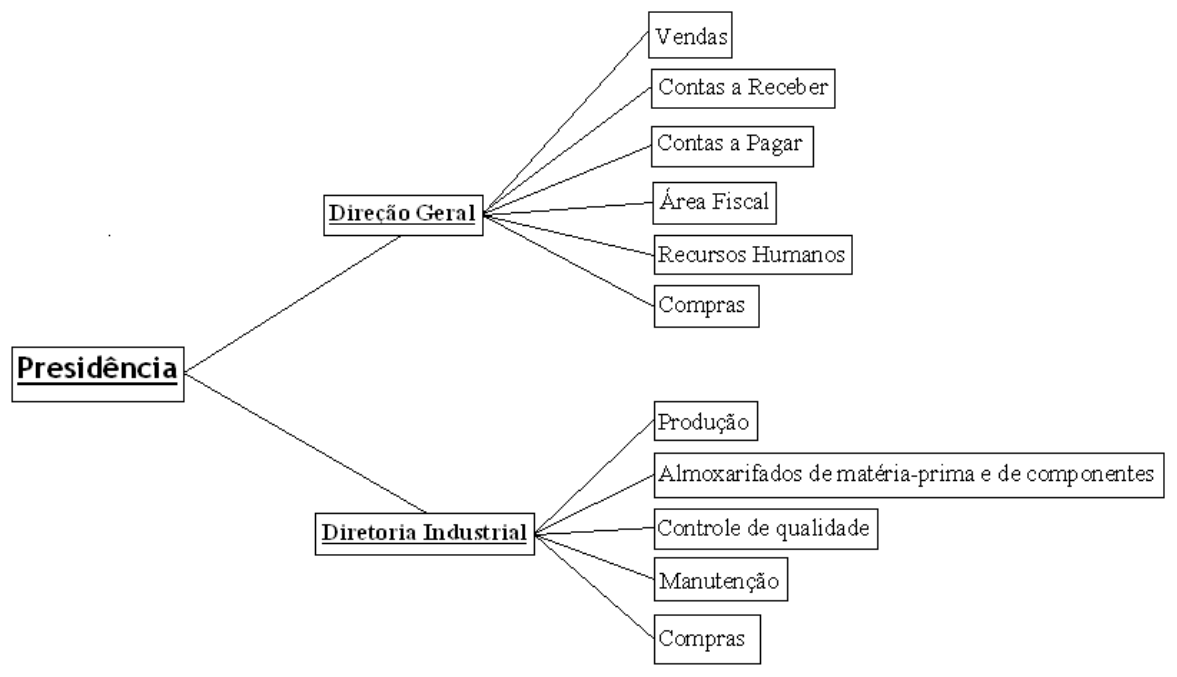

Figura 2 - Organograma da empresa Fonte: empresa estudada.

A estrutura da empresa é a mesma desde que foi criada, não há filiais em outros países, na verdade só existe uma filial que é em São Paulo. 


\subsection{Objetivos da empresa}

Em relação aos objetivos da empresa, não existe nenhum documento que formalize esses objetivos. Esses objetivos não sofrem ordem de prioridades. Eles se mantiveram os mesmos durante os últimos três anos. Não existe um detalhamento desses objetivos em gerais e específicos.

Não existe nenhuma forma de avaliação dos resultados obtidos em relação aos seus objetivos. Não existe nenhum processo de integração formal entre os objetivos de curto prazo e suas metas específicas. Esses objetivos foram perseguidos durantes esses últimos três anos. O objetivo que conta é a lucratividade.

Em função de uma disputa cada vez mais acirrada no mercado, com o surgimento de um sem-número de opções para os clientes, conquistar novos clientes e manter os já conquistados tornou-se uma batalha sem fim nos últimos anos.

Além disso, a ocorrência de mudanças nas equipes de vendas em pontos estratégicos, ora com bons resultados, ora com resultados razoáveis, bem como o surgimento de encargos fiscais e sociais mais abrangentes, fizeram com o lucro se tornasse uma realidade distante.

\section{ANÁLISE DO CASO}

A seguir é apresentada uma análise do caso da empresa estudada. Para tanto, foi feita uma comparação daquilo foi identificado na empresa e o que é discutido nas principais obras encontradas sobre controle gerencial.

\subsection{Sistema contábil}

Em relação ao sistema contábil não foi possível identificar em que momento existe um afastamento ou proximidade em relação à literatura estudada.

A pesquisa foi realizada em um período em que é dado para alguns empregados, em função das festas de fim e início de ano, férias coletivas. Com isto, algumas das pessoas responsáveis pelo setor não estavam disponíveis no momento em que foi realizada a pesquisa.

\subsection{Centros de Responsabilidade}

Da literatura trabalhada, no que diz respeito à abordagem sobre Centros de Responsabilidade, Centros de Investimento é o centro em que o desempenho é medido pelo lucro obtido e pelos bens que ele usa, ou seja, os lucros têm relação com o capital investido (ANTHONY; GOVINDARAJAN, 2006, p. 185).

Identificou-se na Empresa como centro de responsabilidade o Centro de Investimento. O foco principal da empresa é o lucro alcançado. Existe uma formalização das funções do chefe do centro de investimento principais. As metas de desempenho são acompanhadas através de gráficos.

\subsection{Preços de Transferência}

Existe uma tendência atual no sentido da descentralização. A grande dificuldade disto consiste em saber qual é o melhor método na contabilização de serviços e produtos transferidos nas unidades de negócios em sistemas descentralizados diante de grandes demandas dessas transações. O preço de transferência não é um mecanismo essencialmente contábil, ele serve para a distribuição de receitas entre dois ou mais centros responsáveis pelas várias etapas na produção do produto. Assim, o preço de transferência serve como um instrumento que motiva os gestores a adotarem as decisões corretas (ANTHONY; GOVINDARAJAN, 2006, p. 271). 
Foi observado no caso que não existe na empresa nenhum mecanismo formal que regule o fluxo interno de bens e serviços entre os principais centros de responsabilidade. A única atribuição de responsabilidade diz respeito às vendas. Não existe de preço de transferência a nenhum responsável. Não existe distribuição de receita, a atividade de vendas é quem recebe a receita gerada, sem compartilhamento.

\subsection{Sistemas de Controle Gerencial}

A literatura trabalhada apresenta quatro tipos de sistemas de controle: Controle Familiar, Controle Ad-hoc, Controle Burocrático e Controle por Resultados. Dentre os tipos de controle apresentados por Gomes e Salas (2006, p.20), o que mais se aproxima do tipo da empresa estudado é o Controle Familiar.

De acordo com as definições sobre tipos de controles organizacionais dadas por Gomes e Salas (2001, p. 60), aquela que mais se apresenta próxima do que foi identificado na empresa é o Controle Familiar. A definição que Gomes e Salas (2001, p. 60) trazem deste tipo de controle é:

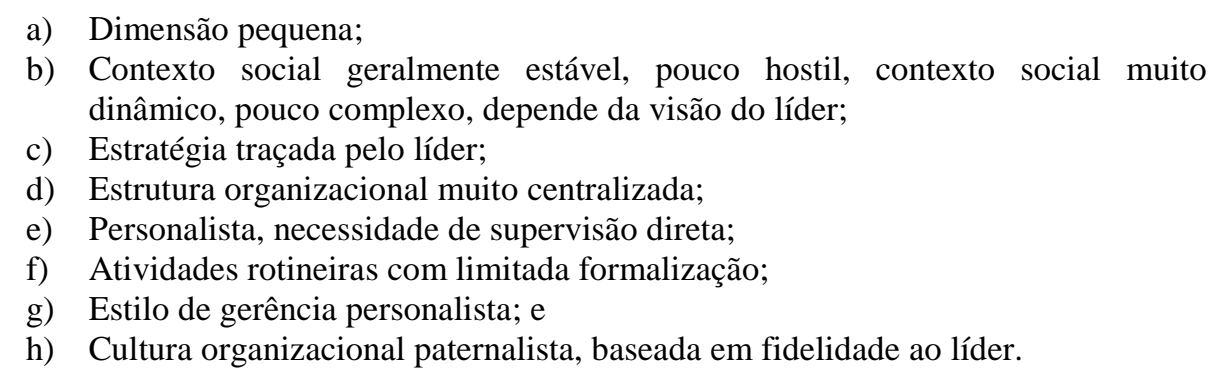

No Caso Estudado não existe um sistema de controle gerencial formalizado na empresa. Sua estrutura hoje é pequena, as estratégias são definidas pela direção da empresa, centralizada em uma pessoa e não há uma formalização das tarefas da empresa.

\subsection{Avaliação de Desempenho}

Anthony e Govindarajan (2006, p. 277) apontam a assertividade da utilização do centro de lucro como parâmetro na avaliação de desempenho em uma empresa, dessa forma possibilita à administração a adoção de uma medida universal.

No caso estudado, a avaliação é centrada nos resultados das vendas apenas, e sua forma de incentivo é unicamente o percentual de comissão sobre as vendas.

\section{CONCLUSÃO}

Embora a empresa tenha apresentado no passado uma posição confortável em relação à atuação internacional, hoje isto acontece em pequena escala, onde os contratos internacionais fechados pela empresa se dão em função das vendas de reposição dos produtos que não podem ser substituídos por outras marcas de produtos similares. Por causa das próprias características dos equipamentos que precisam utilizar as chaves eletromecânicas (tamanho, forma, etc.).

A atuação da empresa em outros mercados no passado foi fruto de um acordo de parceria que ela realizou com a multinacional do setor, acordo este que já não existe há certo tempo. Os contratos foram feitos em função da multinacional envolvida na parceria ter um ônus menor nos seus custos para buscar novos mercados.

Ou seja, um caminho que pode ser perseguido pelas empresas no processo de internacionalização é na constituição de contratos de parcerias. Entretanto, estes contratos 
devem ser muito bem elaborados, para que as empresas brasileiras não sejam utilizadas pelas grandes empresas de outros países como ferramentas de expansão dos negócios dessas multinacionais e depois serem descartadas quando o seu produto já estiver sido bem colocado nos novos mercados.

No caso estudado, o processo de internacionalização da empresa sempre se deu por meio da exportação de seus produtos para a América Latina. Durante a existência da parceria, as exportações alcançavam as cifras de milhões, o que já não acontece mais.

A sua manutenção no mercado internacional continua acontecendo em função da reposição dos equipamentos nos processos de manutenção apenas, quando existe a especificação do produto já utilizado no local ou equipamento. $\mathrm{O}$ que torna o produto fabricado pela empresa um produto exclusivo. Ou seja, o único a poder ser utilizado na reposição, sem condições de utilização dos similares existentes.

Ao longo do tempo de existência da empresa, não houve alterações relevantes na estrutura da mesma. Permanecendo ela praticamente da mesma forma desde quando foi criada. Conclui-se com isto que pode ter havido por parte da empresa certa acomodação diante do processo de internacionalização.

Existem poucos pontos coincidentes entre aquilo que é apresentado na literatura e o que foi identificado na empresa estudada. Sistema de controle gerencial (o controle familiar), a avaliação de desempenho e centros de responsabilidade foram os aspectos que se aproximaram daquilo que é apresentado na literatura. Em relação aos preços de transferência foi verificado um afastamento daquilo que foi na revisão da literatura.

Provavelmente pela falta de um sistema de controle gerencial adequado, acontecido na empresa durante o processo de internacionalização e também fora dele, é que, mesmo tendo conquistado o mercado internacional da América Latina, a empresa não conseguiu manter a sua posição após a perda do contrato de parceria.

Como sugestão para novas pesquisas propõe-se o estudo comparativo do sistema de controle gerencial de outras empresas internacionalizadas no setor, investigando quais os fatores que foram preponderantes para as mesmas no processo de internacionalização e a importância do sistema de controle gerencial nesse processo.

\section{REFERÊNCIAS}

ALEM, Ana Claudia; CAVALCANTI, Carlos Eduardo. O BNDES e o apoio à internacionalização das empresas brasileiras: algumas reflexões. Revista do BNDES, Rio de Janeiro, v. 12, n. 24, p. 43-76, dez., 2005.

AMAL, Mohamed; SEABRA, Fernando. Determinantes do Investimento Direto Externo (IDE) na América Latina: uma perspectiva institucional. Economia, Brasília, v. 8, n. 2, p.231247, maio/ago. 2007. Disponível em: <http//www.anpec.org.br/revista/vol8/vol8n2p231_247.pdf>. Acesso em: 18 jun. 2009.

ANTHONY, Robert N.; GOVINDARAJAN, Vijay. Sistemas de controle gerencial. São Paulo: Atlas, 2006.

ANTRÀS, Pol; HELPMAN, Elhanan. Global sourcing. Harvard University, Tel Aviv University, and CIAR, Dec., 2003

ATKINSON, Anthony A.; BANKER, Rajiv D.; KAPLAN, Robert S.; YOUNG, S. Mark. Contabilidade gerencial. Traduzido para o português por André Olímpio Mosselman Du Chenoy Castro. São Paulo: Atlas, 2000. 
BOURGUIGNON, Annick; MALLERET, Véronique; NORRKLIT, Hanne. The American balanced scorecard versus the French tableau de bord: the ideological dimension. Management Accounting Research, Elsevier, n. 15, p. 107-134, 2004.

CARVALHO, Adriane M. A.; SANTOS, Amanda B. A. Estratégia para a promoção da inclusão digital: proposta de Balanced Scorecard para o Comitê de Democratização da Informática - Regional de Minas Gerais. Disponível em: <www.cinform.ufba.br/vi_anais/docs.AdrianeMariaArantesCarvalho.pdf >. Acesso em: 02 fev. 2009.

CASELLI, Francesco; FEYRER, James. The marginal product of capital. Paper presented at the 7th Jacques Polak Annual Research Conference. Hosted by the International Monetary Fund. Washington, p. 9-10, DC-Nov. 2006.

COLISS, Jill; HUSSEY, Roger. Pesquisa em administração: um guia prático para alunos de graduação e pós-graduação. 2 ed. Traduzido para o português por Lucia Simonini. Porto Alegre: Bookman, 2005.

DRUCKER, Peter. Desafios gerenciais para o século XXI. São Paulo: Pioneira, Thomson Learning, 1999.

EUROPEAN SMEs, Observatory. Internationalisation of SMEs. Entreprise publications, 2003/4.

GOMES, Josir Simeone. Controle gerencial na era da globalização. Rio de Janeiro: Coppead/UFRJ - $\quad$ Relatórios, $1997 . \quad$ Disponível em: <http://www2.coppead.ufrj.br/port/index.php?option=com_docman\&Itemid=204\&task=cat_v iew\&gid=54\&dir=DESC\&order=date\&limit=10\&limitstart=50>. Acesso em: 02 fev. 2009.

GOMES, Josir Simeone; AMAT, Joan M. S. Controle de gestão: uma abordagem contextual e organizacional: textos e casos. São Paulo: Atlas, 2001.

GOMES, Josir Simeone; CAVALCANTI, Antonio Cesar Lins; PINHEIRO, Márcia Maria Alves; BARROSO, Suzana Rezende. Management control in the internationalized Brazilian firm: the case of Calçados Azaléia S.A. In: BALAS Conference, 2001, San Diego. Anais ... San Diego, abr. 2001.

GOMES, Josir Simeone; MATOS, Felipe F. J.; ROSA, Wagner de Castro C.; PALMEIRO, Marcos A.; GABEIRA NETTO, Luiz J. Management control in the internationalized firm: the case of Praxair Inc. In: BALAS Conference, 2001, San Diego. Anais ... San Diego, abr. 2001.

GOMES, Josir Simeone; MARTINEWSKI, André L. More evidences on management control in internationalized Brazilian companies. In: BALAS Conference, 2001, San Diego. Anais ... San Diego, abr. 2001.

GOMES, Josir Simeone; MARTINEWSKI, André L. Management control in internationalized Brasilian companies: a nine case study. In: Fifth International Management Control Systems Research Conference-Controlling Systems and Systems of Control, 5., Royal Holloway. Anais... Royal Holloway, University of London, 2001.

GOMES, Josir Simeone; SOUZA, Daniel Alves A.; MELLO, Leila Batista; OLIVEIRA, Patricia Lopes. Management control in the internationalized Brazilian bank: the case of Banco do Brasil S.A. In: Congresso Internacional de Custos, 2001, Leon. Anais ... Leon, España, 2001. 
GOMES, Josir Simeone; MARTINEWSKI, André L. Controle gerencial em empresas brasileiras internacionalizadas: algumas evidências em empresas do setor de serviços. In: ENANPAD, 2001, Campinas. Anais... Rio de Janeiro: ANPAD, 2001.

GOMES, Josir Simeone; BARBOSA, José Geraldo. Um estudo exploratório do controle gerencial de ativos e recursos intangíveis (capital intelectual) em empresas brasileiras. In: ENANPAD, 2001, Campinas. Anais... Rio de Janeiro: ANPAD, 2001.

HANSEN, Don R.; MOWEN, Maryanne M.. Gestão de custos. Traduzido para o português por Robert Brian Taylor. São Paulo: Pioneira, Thomson Learning, 2003.

HORNGREN, Charles T.; FOSTER, George; DATAR, Srikat M.. Contabilidade de custos. 9 ed. Traduzido para o português por José Luiz Paravato. Rio de Janeiro: LTC, 2000.

HORNGREN, Charles T.; SUNDEN, Gary L.; STRATTON, William O. Contabilidade gerencial. 12 ed. Traduzido para o português por Elias Pereira. São Paulo: Pearson Prentice Hall, 2004.

IEP. Masterdroit et globalisation économique: introduction to international trade. In: Seminar Trade and investiment, 7., Paris, 2007. Disponível em: <http://www.supportscoursenligne.sciences-po.fr/2007_2008/economie_commerce/IIT7.pdf>. Acesso em: 02 fev. 2009.

JONES, Ronald; KIERZKOWSKI, Henryk. International trade and agglomeration: an alternative framework. HEI Working Paper, n. 10/2004.

JUNQUEIRA, Emanuel Rodrigues; MORAES, Romildo de Oliveira. Preços de transferência: reflexos de sua utilização na avaliação do desempenho dos gestores de áreas de responsabilidade. Revista Universo Contábil, v. 1, n. 3, p. 37-47, set./dez. 2005.

KEITH, Lyman A,; KEITH, Richard L. Accounting: a management perspective. New Jersey: Prentice-Hall, 1985.

KAPLAN, Robert S.; NORTON, David P.. Balanced Scorecard: mapas estratégicos. Rio de Janeiro: Elsevier, 2004.

NORREKLIT, Hanne. The Balanced Scorecard: what is the score? A rhetorical analysis of the Balanced Scorecard. Accounting, Organizations and Society, v. 28, p. 591-619, 2003. http://dx.doi.org/10.1016/S0361-3682(02)00097-1

PADOVEZE, Clóvis L. Contabilidade gerencial: um enfoque em sistema de informação. 4 ed. São Paulo: Atlas, 2004.

SILVA, José Alberto Teixeira; SANTOS, Roberto Fernandes; SANTOS, Neusa Maria Bastos S.. Criando valor com serviços compartilhados: Balanced Scorecard. Rio de Janeiro: Saraiva, 2006.

WARREN, Carl S.; REEVE, James M.; FESS, Philip E.. Contabilidade gerencial. 6 ed. Traduzido para o português por André O. D. Castro. São Paulo: Pioneira, Thomson Learning, 2001. 